\title{
Prevalence of hepatitis B and C in pregnant ladies and their neonates in minia governorate
}

\begin{abstract}
Objective: Infection with hepatitis B virus (HBV) and hepatitis C (HVC) in pregnant women is not uncommon and have a threat for both mothers and fetuses. This study was performed to explore the true prevalence of $\mathrm{HBV}$ and $\mathrm{HCV}$ and incidence of neonatal transmission in Minia locality.

Methods: This is a prospective cohort study was conducted at the maternity and pediatric Hospital Minia University in the period between January 2015 till December 2016 all women coming in labour was included in this study. The main outcomes were the prevalence of hepatitis B and C in women and incidence of neonatal transmission.

Results: Total number of women accepted sharing in our study was 11250 ladies. Total number of infected cases was 135 patients $(1.2 \%), 84$ of them were HCV $+\mathrm{ve}(0.75 \%)$ and 41 cases HBV+VE ( $0.364 \%)$ while 10 cases were mixed infection $(0.089 \%)$, 102 patient $(75.5 \%)$ of infected cases from rural areas while 33 patient $(24.5 \%)$ from the urban areas. Total number of acquired neonatal hepatitis at delivery was 7 cases only, then after 3 months reassessment shows another 3 cases, So total number of infected babies after three months follow up was 10 cases out of 135 maternal cases in a percentage of $7.4 \%$.

Conclusion: Hepatitis infection is a public and social problem affecting some pregnant women in Egypt and need to be fully discovered and to be well investigated to reduce the incidence of new cases and to counteract against flare up of new infection with consequences for both mothers and newborns, and the relative lack of data, make this a critical medical challenge.
\end{abstract}

Keywords: pregnancy hepatitis b and c virus infection, neonatal transmission, HBV, HVC
Volume 4 Issue I - 2018

\author{
Reham R Elkhateeb, Hany H Kamel \\ Department of obstetrics and gynaecology, Minia University, \\ Egypt
}

Correspondence: Reham R Elkhateeb, Department of
obstetrics and gynaecology, Faculty of Medicine, Minia
University, Egypt, Email rehamelkhateeb78@yahoo.com

Received: December 13,2017 | Published: February 16, 2018

\section{Introduction}

Hepatitis B virus (HBV) and hepatitis $\mathrm{C}$ virus $(\mathrm{HCV})$ are acquired by contaminated blood product exposure, sexual activity, perinatal transmission are also important source of infection. ${ }^{1}$ Women during childbearing age have a 1 to $2 \%$ incidence of chronic HCV infection, with higher rates in those with risk factors like patients undergone hemodialysis. ${ }^{2}$ Pregnancy in patients with chronic HBV or HCV is associated with mother-to-child transmission (MTCT) and may be associated with increased maternal and fetal complications. ${ }^{3}$

Maternal infection with either HBV or HCV has been linked to adverse pregnancy and birth outcomes, including MTCT. MTCT for HBV has been reduced to approximately $5 \%$ overall in countries including the US that have instituted postpartum neonatal HBV vaccination and immunoprophylaxis with hepatitis $B$ immune globulin. ${ }^{4}$

Hepatitis C represents about $20 \%$ of acute hepatitis and $70 \%$ of chronic hepatitis, Africa reported to have the highest HCV prevalence rate. ${ }^{5}$ Peri-natal and post-natal transmission of $\mathrm{HCV}$ via close contact, saliva, and breast feeding is possible of about $5 \%$ among HCV -RNA positive pregnant women. ${ }^{6}$ Vertical transmission of HCV from mother to neonates occurs in $3-10 \%$ of pregnancies complicated by maternal HCV infections. ${ }^{7}$

However, in the absence of appropriate prophylaxis, $40 \%$ of the neonates of $\mathrm{HBe} \mathrm{Ag}$ negative mothers and $90 \%$ of the neonates of $\mathrm{HBe} \mathrm{Ag}$ positive mother will develop HBV infection. ${ }^{8}$ World Health Organization estimates chronic hepatitis infection more than 240 million people worldwide. ${ }^{9}$ In highly endemic countries, mother-to-child transmission accounts for most cases of infections and is, therefore, the main mechanism that maintain infection in the population. ${ }^{10-12}$

For these patients, new guidelines from the European Association for the Study of the Liver (EASL) and the Asian Pacific Association for the Study of the Liver (APASL) indicate that, in addition to neonatal vaccination and immunoprophylaxis, treating with antiviral agents such as tenofovir disoproxil fumarate or telbivudine during pregnancy beginning at 32 weeks of gestation is safe and effective in preventing MTCT. ${ }^{13}$

\section{Patient and methods}

Total number of patient 11250,84 cases HCV, 41cases HBV, 10 Cases mixed, 135 cases with positive hepatitis infection. In this prospetive observational study we aim to discover the accurate prevalence of $\mathrm{HBV}, \mathrm{HCV}$, among pregnant ladies coming in labor at maternity hospital minia university incidence of transmission among the neonates of infected women.

The study was conducted during the period between January 2015 till December 2016, after being accepted by the department ethical committee on 22nd December 2014, approval number 276/2014. 
Inclusion criteria: All ladies coming in labor to the emergency department included in our study, all details about the study were explained to patients, informed and a written consent taken before being enrolled in the study.

For all ladies the following done: Complete blood count, liver function tests, HBVS antigen, HCV antigen.

The diagnosis of hepatitis B done by testing hepatitis B surface antigen. All patients with $\mathrm{C}$ infection were positive for hepatitis $\mathrm{C}$ antibodies and PCR. For diagnosis of vertical transmission of hepatitis in the newborn, we used HBs antigen for B virus and HCV RNA PCR, as antibodies of hepatitis $\mathrm{C}$ are transmitted through the placenta.

Labor allowed according to the obstetric progress, then the neonates assessed by pediatrician for APGAR scoring, and cord blood sampling taken for $\mathrm{CBC}$, liver function and hepatitis $\mathrm{B}$ and $\mathrm{C}$ markers then repeated after three months for all -ve neonates of infected mothers.

Then follow up of the result done which statistically studied.

\section{Results}

Total number of women accepted sharing in our study was 11250 ladies of all minia governorate areas Sociodemographic criteria were incomparable as regard age, parity, body weight, however it was significantly different among hepatititic patients as the prevalence in rural area was more than urban areas. ladies.

Total number of women accepted sharing in our study was 11250

Total number of infected cases was 135 patients (1.2\%), 84 of them were $\mathrm{HCV}+\mathrm{ve}(0.75 \%)$ and 41 cases $\mathrm{HBV}+\mathrm{VE}(0.364 \%)$ while 10 cases were mixed infection $(0.089 \%), 102$ patient $(75.5 \%)$ of infected cases from rural areas while 33 patient(24.5\%) from the urban areas.

Total number of acquired neonatal hepatitis at delivery was 7cases only, then after 3 months reassessment shows another 3 cases. So total number of infected babies after three months follow up was 10 cases out of 135 maternal cases in a percentage of $7.4 \%$ (Tables 1-3).

Table I Sociodemographic criteria of the study population

\begin{tabular}{lll}
\hline Parameter & Number(n I I 250) & P value \\
\hline Residence & & \\
Rural & $7313(65 \%)$ & 0.03 \\
Urban & $3937(35 \%)$ & \\
Parity & & \\
Primigravidae & $5062(45 \%)$ & 0.6 \\
Multigravidae & $6188(55 \%)$ & \\
Known hepatitits & \\
Yes & $9(0.08 \%)$ & 0.0004 \\
No & $11241(99.92 \%)$ & \\
Previous surgery & \\
Yes & $3937(35 \%)$ & 0.03 \\
No & $7313(65 \%)$ & \\
\hline
\end{tabular}

\begin{tabular}{lll} 
Table Continued... & & \\
\hline Parameter & Number(n I I 250) & P value \\
\hline History of bilharziasis & & \\
Yes & II $(0.097 \%)$ & 0.0004 \\
No & I I $239(99.903 \%)$ & \\
Mode of delivery & \\
Normal delivery & $9168(81.49 \%)$ & \\
Instrumental & $395(3.6 \%)$ & \\
CS & I687(14.9\%) \\
\hline
\end{tabular}

Table 2 prevalence of hepatitis among study population

\begin{tabular}{lll}
\hline Types of hepatitis & Number (135) & Percentage \\
\hline Hepatitis B +ve & $4 \mathrm{I}$ & $30.30 \%$ \\
Hepatitis C +ve & 84 & $62.20 \%$ \\
Mixed infection & 10 & $7.50 \%$ \\
\hline
\end{tabular}

Table 3 Neonatal outcome of infected women

\begin{tabular}{llll}
\hline Types of hepatiti & At delivery & $\begin{array}{l}\text { After 3 } \\
\text { months }\end{array}$ & $\begin{array}{l}\text { Total } \\
\text { number }\end{array}$ \\
\hline +ve Mothers (4I) Hepatitis B & 2 & $\mathrm{I}$ & $3(7.3 \%)$ \\
Hepatitis c +ve Mothers (84) & 4 & 2 & $6(7.1 \%)$ \\
Mixed infection Mothers(I0) & $\mathrm{I}$ & 0 & $\mathrm{I}(10 \%)$ \\
\hline
\end{tabular}

\section{Discussion}

There is a great difference in the prevalence of HBV between developed and developing countries as it varies between $2 \%$ in developed countries to about $8 \%$ in developing countries where infection is endemic with sex, age and socioeconomic status as important risk factors for infection. ${ }^{14}$

Countries are classified as having low endemic rates $(<2 \%)$, intermediate endemic rates $(2-8 \%)$, or high endemic rates $(>8 \%)$ positive for HBsAg. ${ }^{15}$ The prevalence of $\mathrm{HBV}$ in Egypt is of intermediate endemicity $(2-8 \%) .{ }^{16}$ Our results are in agreement with that of Khalil et al. ${ }^{17}$ from Saudi Arabia who reported that $2.4 \%$ of their studied women were positive for $\mathrm{HBsAg}^{17}$ but not in accordance with Eke et al. ${ }^{18}$ from Nigeria and Sharifi et al. ${ }^{19}$ from Iran reported higher prevalence rates of $\mathrm{HBV}$ of $8.3 \%$, and $6.5 \%$ respectively .

Zahran et al..$^{20}$ have documented a lower prevalence of HBsAg and anti-HCV among pregnant women in Egypt as $4.0 \%$ and $6.4 \%$ in Egypt. ${ }^{20}$ Although Egypt thought to be endemic for HBV and HCV infection, still the rate of infection is low among pregnant ladies which attributed to change the practice of female circumcision which was bad tradition in the past it was performed in a ceremony for a group of young girls under unsterile circumstances.

Also the lower rate of infection may be due to increasing level of public awareness of the risk of infection in different public clinics and hospitals, increase educational level of delivered women who give high consideration for sterile equipment and increase programs of nurse training that follow aseptic precautions.

Our study showed that the rate of infection is higher among rural areas $(65 \%)$ than urban areas $(35 \%)$ which reflects the higher educational level and public awareness of infection among urban than 
rural women. Also the high rate of home delivery which conducted by untrained midwives using non sterile instruments contributing to increased rate of hepatitis infection among those ladies. In this study the rate of vertical transmission was $12 \%$ in HBV cases (3 neonates out of 25 mother) and for $7.1 \%$ HCV cases (6 neonates out of 84 mothers) which also shown to be much less than the international records which documented that $30 \%$ to $40 \%$ of chronically infected HBV patients are due to perinatal transmission. ${ }^{21}$

Transmission risk of Hepatitis $\mathrm{C}$ virus is much lesser, since it is about $5 \%$ for women who are positive for viral RNA at the end of pregnancy. At-risk neonates who received HBV vaccine alone at birth had a 26 to $36 \%$ chance of MTCT of HBV infection, whereas administration of HBIG alone at birth decreased the rate of perinatal HBV transmission to 15 to $20 \% .^{22}$

If $\mathrm{HBIG}$ and the $\mathrm{HBV}$ vaccine are administered to the neonate of an HBsAg-positive mother within $12 \mathrm{~h}$ of delivery, approximately $5 \%$ of infants become chronic HBV carriers, a reduction in MTCT of almost $90 \%$. Overall, the use of HBIG and HBV vaccine has reduced MTCT to 5 to $10 \%{ }^{23}$

\section{Recommendation}

Although hepatitis infection is decreasing our locality still an endemic area for infection, hepatitis infection screening must be obligatory for all pregnant women during ANC visits to decrease cross and vertical transmission. Further studies are needed to evaluate the effectiveness of antiviral use during pregnancy which may further helping in limiting the horizontal or vertical transmission of different hepatitis viruses in our community.

\section{Acknowledgements}

None.

\section{Conflict of interest}

Author declares that there is no conflict of interest.

\section{References}

1. Connell LE, Salihu HM, Salemi JL, et al. Maternal hepatitis B and hepatitis C carrier status and perinatal outcomes. Liver Int. 2011;31(8):1163-1170.

2. Rustgi VK. The epidemiology of hepatitis $\mathrm{C}$ infection in the United States. J Gastroenterol. 2007;42(7):513-521.

3. Ott JJ, Stevens GA, Groeger J, et al. Global epidemiology of hepatitis $B$ virus infection: New estimates of age-specific HBsAg seroprevalence and endemicity. Vaccine. 2012;30(12):2212-2219.

4. Reddick KL, Jhaveri R, Gandhi M, et al. Pregnancy outcomes associated with viral hepatitis. J Viral Hepat. 2011;18(7):e394-e398.

5. Conte D, Fraquelli M, Prati D, et al. Prevalence and clinical course of chronic hepatitis $\mathrm{C}$ virus (HCV) infection and rate of $\mathrm{HCV}$ vertical transmission in a cohort of 15,250 pregnant women. Hepatology. 2000;31(3):751-755.
6. Andre FE, Zuckerman AJ. Review: protective efficacy of hepatitis B vaccines in neonates. J Med Virol. 1994;44(2):144-151

7. Ohto H, Terazawa S, Sasaki N, et al. Transmission of hepatitis $\mathrm{C}$ virus from mothers to infants. The Vertical Transmission of Hepatitis C Virus Collaborative Study Group. N Engl J Med. 1994;330(11):744-750.

8. Yang J, Zeng XM, Men YL, et al. Elective caesarean section versus vaginal delivery for preventing mother to child transmission of hepatitis B virus--a systematic review. Virol J. 2008;5:100.

9. World Health Organization. Hepatitis B. Geneva: WHO; 2013.

10. Borgia G, Carleo MA, Gaeta GB, et al. Hepatitis B in pregnancy. World J Gastroenterol. 2012;18(34):4677-4683.

11. Jonas MM. Hepatitis B and pregnancy: an underestimated issue. Liver Int. 2009;29(Suppl 1):133-139.

12. Lavanchy D. Chronic viral hepatitis as a public health issue in the world. Best Pract Res Clin Gastroenterol. 2008;22(6):991-1008.

13. European Association For The Study Of The Liver. EASL clinical practice guidelines: Management of chronic hepatitis B virus infection. J Hepatol. 2012;57(1):167-185.

14. Odusanya OO, Alufohai FE, Meurice FP, et al. Prevalence of hepatitis $B$ surface antigen in vaccinated children and controls in rural Nigeria. International J Infect Dis. 2005;9(3):139-143.

15. Sharma P, Steele RW. Pediatric Hepatitis B. 2011.

16. El-Zayadi A. Hepatitis B Virus Infection the Egyptian Situation. Arab J Gastroenterol. 2007;8:94-98.

17. Khalil MK, Al-Mazrou YY, Al-Jeffri M, et al. Serosurvey of hepatitis B surface antigen in pregnant Saudi women. East Mediterr Health J. 2005;11(4):640-647.

18. Eke AC, Eke UA, Okafor CI, et al. Prevalence correlates and pattern of hepatitis B surface antigen in a low resource setting. Virol J. 2011;8:12.

19. Sharifi-Mood B, Keykhah F, Moghadam ES, et al. Prevalence of Hepatitis B Surface Antigen in Pregnant Women in Zahedan, Iran. Hepat Mon. 2004;4:161-163.

20. Zahran KM, Badary MS, Agban MN, et al. Pattern of hepatitis virus infection among pregnant women and their newborns at the Women's health center of Assiut University, upper Egypt. Int J Gynaecol Obstet. 2010;111(12):171-174.

21. Libbus MK, Phillips LM. Public health management of perinatal hepatitis B virus. Public Health Nurs. 2009;26(4):353-361.

22. Pan CQ, Duan ZP, Bhamidimarri KR, et al. An algorithm for risk assessment and intervention of mother to child transmission of hepatitis B virus. Clin Gastroenterol Hepatol. 2012;10(5):452-459.

23. Soleimani Amiri MJ, Hasanjani Roushan MR, Baiany M, et al. Outcomes of passive-active immunoprophylaxis given to infants of mothers infected with hepatitis B virus in Babol, Iran. $J$ Clin Virol. 2010;49(4):283-285. 